\title{
O Progressismo de Pares de Steven Johnson em uma Sociedade em Rede ${ }^{1}$ \\ Gustavo Luiz FERREIRA SANTOS ${ }^{2}$
}

JOHNSON, Steven. Future Perfect: The Case for Progress in a Networked Age. [ebook]. Riverhead, 2012. ISBN 978-1-59448-820-7.

As pessoas trocariam as circunstâncias confortáveis de seu dia-a-dia no séc. XXI para viver em uma época em que o desenvolvimento tecnológico e científico ainda não nos tivesse proporcionado melhorias em saúde, transporte e comunicação? Essa é a pergunta suscitada da leitura do argumento inicial da obra escrita por Steven Johnson "Future Perfect: A case for progress in a conected age", , ainda não lançado no Brasil, aqui resenhado em sua versão e-book e por essa razão, sem referências às páginas citadas.

O livro inicia destacando a relevante proposição sobre a falta de percepção dos avanços incrementais alcançados pela sociedade e a valorização do espetáculo das grandes descobertas ou fracassos pela mídia, mas rapidamente abandona tal ponto para que o autor fixe seu foco na busca por relacionar uma lógica inerente à internet a um princípio político que possa dar conta de seu "manifesto" em favor do que chama "peer progressives" $"$ e dos exemplos levantados por ele como indicadores desse "novo movimento". Para isso, apresenta índices de avanço social (como a diminuição de acidentes de trabalho, queda no número de divórcios, as admissões escolares, a diminuição da diferença entre salários de homens e mulheres) e se propõe defender que

\footnotetext{
${ }^{1}$ Trabalho apresentado à quarta edição da Revista Ação Midiática - Estudo em Comunicação, Sociedade e Cultura, publicação esta ligada ao Programa de Pós-Graduação em Comunicação da Universidade Federal do Paraná.

${ }^{2}$ Mestrando do setor de Pós-graduação em Comunicação da UFPR, na linha de pesquisa Comunicação Educação e Formações sócio culturais, pesquisa atualmente Formações Socioculturais, Consumo Cultural e Colaboração na Cultura Digital. E-mail: guzferreira@gmail.com

3 A expressão "Future Perfect" em inglês refere-se a um tempo verbal equivalente em português ao "Futuro do Presente", onde um fato ou ação estará completada no futuro. O título faz um trocadilho com a noção de "progressismo" em que pode haver um "futuro perfeito" mantendo-se a sociedade em "progresso".

4 Em referência ao Peer da rede peer-to-peer, ponto-a-ponto ou par-a-par, em que os elementos conectados à rede possuem o mesmo nível hierárquico. Aqui seu significado é compreendido em tradução livre por "progressistas de pares".
} 


\section{REVISTA AÇÃOMIDIÁTICA - Estudos em Comunicação, Sociedade e Cultura}

Universidade Federal do Paraná

Programa de Pós Graduação em Comunicação

Vol 2. No 2. Ano 2012

tais progressos são alcançados pela formação de redes sociais, virtuais ou off-lines, que viabilizam o desenvolvimento e a troca de conhecimentos.

Em sua seção inicial o autor apresenta o caso do aumento dos vôos comerciais nos Estados Unidos e a notável diminuição de acidentes fatais com aeronaves (entre 2007 e 2008, não foi registrado, nos EUA, nenhum acidente fatal em vôos comerciais) para evidenciar esse progresso. Para ele, a tecnologia desenvolvida ao longo dos anos através do acúmulo de conhecimento permitiu a criação de soluções que viabilizaram vôos mais seguros mas, apesar disso, muitas pessoas ainda se recusam a voar baseadas numa percepção que é, segundo o autor, amplificada graças à tendência da sociedade em valorizar os grandes acontecimentos, no caso os acidentes aéreos, em detrimento dos processos longos, lentos e incrementais obtidos pelo acúmulo de pequenas descobertas e ignorar os dados que os comprovam.

Sua "defesa do progresso" continua quando enumera uma série de outras conquistas obtidas com o desenvolvimento da ciência e da tecnologia e que tendem a ser, se não ignoradas, subestimadas na sociedade contemporânea pelo mesmo princípio. O autor assinala que, nos Estados Unidos, desistência escolar, criminalidade juvenil, mortes no trânsito, mortalidade infantil, expectativa de vida, poluição do ar, doações de caridade, participação pelo voto e outros índices melhoraram mais de $20 \%$ em duas décadas. E ainda que, em nível mundial, a quantidade de pessoas vivendo em condições de pobreza caiu pela metade em 50 anos e que, na América Latina, a expectativa de vida e a mortalidade infantil melhoraram em $40 \%$ desde o início da década de noventa.

Esses dados, para Johnson, são desconhecidos, ignorados ou têm sua origem mal interpretada pela opinião pública devido à tendência de favorecer grandes acontecimentos e/ou descobertas. Para ele, porém, não importa discutir se essa tendência tem relação com a psicologia humana ou com o discurso dos meios de comunicação ou ainda com qualquer outro fator, apenas percebê-la é suficiente. Não importa tampouco sugerir um aprofundamento das reais causas das melhorias dos índices apontados. Assim, essa discussão é abruptamente abandonada logo de início para que o autor introduza sua "apologia" ao progresso e a filosofia que, em sua visão, deve reger esse processo.

\footnotetext{
${ }^{5}$ Do título "a case for progress..."
} 
Enquanto enumera a sequência de avanços sociais, mesmo não ignorando que há ainda muitos desafios a serem discutidos, Johnson propõe sua tese de que todas essas soluções não foram encontradas, necessariamente, por sistemas hierárquicos fechados, como governos ou corporações, ainda que ambas estivessem envolvidas de uma forma ou de outra, mas em "redes de pares" (peer networks) com a soma de várias contribuições de diferentes pessoas em pé de igualdade. E ao somar a esse raciocínio o que percebe em empreendedores, comunidades e sites na internet identifica $o$ movimento que chama de "progressista de pares".

Então é assim que me identifico - e muitos de meus amigos e heróis - quando perguntado sobre minha orientação política. Nós acreditamos em progresso social, e nós acreditamos que a ferramenta mais útil para avançar a causa do progresso é a rede de pares. Nós somos progressistas de pares. (Johnson, 2012, tradução nossa) ${ }^{6}$

Sua tese é baseada no movimento progressista americano que emergiu nos anos 70 e acreditava que, em oposição aos conservadores e libertários que defendem o governo mínimo, o Estado deve funcionar como um instrumento para a regulação e desenvolvimento social, mas procura afastar-se do que atualmente convencionou-se chamar de movimento progressista pela esquerda norte-americana, já que, na opinião do autor, tal movimento não está comprometido com o "real progresso".

Essa filosofia parece buscar uma posição de centro no cenário político norteamericano. Ao mesmo tempo em que aponta a relevância do Estado como incentivador da criação das chamadas redes de pares, o autor também se aproxima da posição libertária ao defender que a centralização do poder gera problemas porque o Estado não está diretamente envolvido com as necessidades que só a população, em conexão, pode perceber.

O autor defende, assim, o desenvolvimento da Internet como uma rede descentralizada de comunicação e suas formas de utilização na sociedade contemporânea e afirma que as iniciativas de crowdfunding e crowdsourcing, criadas na web, demonstraram que a colaboração e o trabalho em rede, e não as instituições hierarquizadas, são o principal motor do progresso e que esta percepção, se não se mostra como a solução em si, é um modelo a ser seguido. Para ele, a ARPANET (rede

\footnotetext{
6 "So this is now what I call myself - and many of my friends and heroes - when asked abou tour political orientarion. We believe in social progress, and we believe the most powerful tool to advance the cause of progress is the peer network. We are peer progressives."
} 


\section{REVISTA AÇÃOMIDIÁTICA - Estudos em Comunicação, Sociedade e Cultura}

Universidade Federal do Paraná

Programa de Pós Graduação em Comunicação

Vol 2. No 2. Ano 2012

precursora da internet, desenvolvida pelos militares americanos) e o protocolo TCP/IP (protocolo de comunicação em rede, base para a conexão entre diferentes computadores e linguagens, utilizada nas redes atuais) podem ser considerados "como marcos na história da filosofia política".

Basicamente, Johnson procura identificar uma lógica para a internet, ou "what the internet wants?", apontá-la em outros acontecimentos e movimentos históricos e defender que tal lógica é a descentralização e eliminação das hierarquias. Ele aponta que esse princípio possibilitou o crescimento da Web e de projetos como a Wikipédia, cuja principal característica é a inexistência de um corpo editorial decisor sobre o conteúdo. Para ele, esse é o movimento "progressista de pares" e esse princípio deveria ser apropriado e aplicado politicamente a todas as áreas como, por exemplo, educação, saúde, urbanismo, etc. O livro apresenta, portanto, iniciativas colocadas em prática que traduziriam esse princípio.

$\mathrm{Na}$ segunda parte do livro, o autor elenca uma série de observações acerca desse novo movimento em ação.

- A central de atendimento de Nova York, através do número 311, que concentra reclamações e sugestões da população;

- Jornalismo colaborativo, realizado por iniciativas individuais que são unidas em blogs ou até para grandes meios de comunicação;

- O papel das redes em projetos de crowdfunding no site Kickstarter, no movimento Occupy Wall Street e no recrutamento da Al-qaeda;

- Iniciativas de desafios premiados para a solução de problemas, abertos ao público dentro de empresas privadas;

- O orçamento participativo instituído em Porto Alegre, RS, que passa o processo decisório de destinação de verbas à população por meio de reuniões.

Todas essas iniciativas apresentam, para o autor, traços de uma filosofia que se aproxima muito mais de uma "democracia participativa" do que um "Big Government" ou uma simples solução de mercado. Os desafios de administração urbana, desde buracos nas ruas até casos de lâmpadas quebradas, no caso da central de atendimento 


\section{REVISTA AÇÃOMIDIÁTICA - Estudos em Comunicação, Sociedade e Cultura}

Universidade Federal do Paraná

Programa de Pós Graduação em Comunicação

Vol 2. No 2. Ano 2012

311, de Nova York, são solucionados com a participação da própria população que alerta para os problemas e sugere soluções para eles. Outro exemplo é o financiamento de produtos culturais decidido diretamente pelos interessados a partir de sites de crowdfunding, como o Kickstarter, que transferem o poder decisório para a população, em rede e em pé de igualdade. Tais fatos constituem, segundo o autor, o progresso social.

Para um livro que se propõe descrever e desenvolver uma nova filosofia política, o texto de Steven Johnson mostra-se carente de uma discussão filosófica profunda. Ainda que identifique padrões de comportamento e sociabilidade que emergem com as possibilidades da comunicação digital, o autor não procura confrontar seu pensamento com outras correntes de pensamento e, supreendentemente, não explora o desenvolvimento do conhecimento social e político acumulado ao longo do tempo, além de ignorar proposições importantes como as disputas de poder que podem corromper as redes de pares que descreve.

Seu argumento parece cair em um determinismo tecnológico, ao afirmar que sistemas de participação como a Wikipédia e o Kickstarter, que são possibilitados pelo baixo custo que a comunicação digital oferece, possuem esse princípio básico de colaboração que não possuíam grande amplitude até então, devido aos custos para seu funcionamento em um mundo "pré-internet". Entretanto, ignora que os processos de comunicação são centrais às suas proposições, deixando passar a discussão sobre as razões para a tendência de desvalorização a progressos incrementais e os possíveis problemas que emergem de situações em rede cujas hierarquias, em princípio, foram criadas para resolver.

O texto é declaradamente otimista ao apontar casos em que sua filosofia supostamente estaria sendo apropriada mas se limita a fazer leves aproximações e abrir grandes concessões para que estes princípios se apliquem, como ao afirmar que o canal 311, de Nova York, não é uma completa "rede de pares" mas apesar disso possuiria em sua base a característica principal ao dar à população o poder para a rápida comunicação de problemas. Essa afirmação não leva em conta que o princípio básico de sua defesa, a descentralização, não aparece no canal 311 de Nova York e que, assim, não poderia ser utilizado como exemplo dessa filosofia.

Como em outros livros do autor, a premissa bastante promissora deixa a desejar em sua execução. Evitando o contato direto com a controvérsia, Johnson não se 
preocupa em esgotar seus conceitos e acaba por oferecer um texto generalista, flertando com o determinismo e limitando-se a oferecer evidências anedóticas para evidenciar sua posição. Assim, ainda que seja uma leitura agradável, termina por não contribuir para uma reflexão mais profunda sobre as relações políticas que envolvem a sociedade em rede, apenas um conjunto de casos otimistas e isolados em que a colaboração é potencializada pela comunicação digital. 